\title{
LA ESPIRITUALIDAD PASTORAL COMO ARTE DE DETENERSE ANTE EL MUNDO
}

Autor: Victor Manuel Fernández.

Jesús se fija en cada ser humano, prepara un encuentro con las personas. Caminar y contemplar las cosas en el presente, para situar el dinamismo del propio ser, confiado en el poder de Dios, que nos abre al encuentro con los demás en lo cotidiano.

DOI: https://doi.org/10.52039/seminarios.v49i168.826

Jesús se detenía ante cada ser humano con toda su atención. No era sólo una atención intelectual, sino una mirada de amor:

"Jesús fijó en él su mirada y le amó" (Mc 10, 21).

"Vio a una viuda muy pobre, que ponía dos pequeñas monedas de cobre" (Lc 21, 2).

Jesús invitaba a sus discípulos a prestar atención, a contemplar las cosas y la vida, a percibir el mensaje de la naturaleza:

"Miren los lirios del campo" (Lc 12, 27).

Aquí encuentro una clave de la espiritualidad, particularmente importante para quienes desarrollan una actividad evangelizadora, 1lamados a vivir la espiritualidad en el encuentro con las personas y con el mundo externo. ${ }^{1}$

${ }^{1}$ Aplico aquí a la espiritualidad pastoral cuestiones más ampliamente desarrolladas en una obra de próxima aparición: Claves para vivir en plenitud, San Pablo, Madrid 2003. 


\section{Ansiedad que envenena}

Pero hay una perturbación que nos impide detenernos: la ansie$d a d$. Es una especie de prisa permanente. La persona puede aparecer serena por fuera, pero por dentro está acelerada. Siente una necesidad urgente de resolver pronto todos los problemas, como si todo fuera urgente o indispensable. Quiere terminar rápidamente todo lo que tiene que hacer, sin dejar nada pendiente. Entonces, su mente siempre va más adelante que su cuerpo. Cuando está haciendo algo, está pensando en lo que tendrá que hacer después. No se detiene en nada con profundidad, no está con todo su ser en ninguna tarea, en ninguna cosa. Su cuerpo está en una parte, su mente en otra, sus deseos en otra. Así vive interiormente fragmentado y roto:

"Mucho antes de terminar lo que uno tiene entre manos, la mente corre hacia las próximas tareas. Y es que una vez que se ha caído en la trampa de la prisa, ésta nos fustiga sin piedad creando un estado de ansiedad perturbador. Es importante, sin embargo, saber distinguir la prisa, que es un estado de zozobra, de una acción rápida y libre. Podemos, por ejemplo, correr una maratón y disfrutar de una experiencia que nada tiene que ver con la ansiedad y la angustia, simplemente porque disfrutamos corriendo, y podemos, por el contrario, permanecer todo el día tumbados en el sofá, físicamente inermes, pero angustiados por todas las cosas que debemos hacer y no hacemos"2.

El que ha caído en las redes de la ansiedad tampoco dedica toda su atención a las personas que trata, y esto perjudica la calidad de su acción evangelizadora. Escucha a las personas pensando en lo que tiene que decir o en lo que tendrá que hacer luego. Así se priva de la riqueza de las relaciones sanas y fraternas.

Esa ansiedad es un veneno. No nos permite gozar de lo que hacemos, y provoca una permanente tensión interior. Esa tensión psicológica termina afectando al cuerpo, que no puede resistir esa prisa permanente del sistema nervioso.

Pero aprender a detenernos no sólo nos libera de la ansiedad. La capacidad de detenernos, al ponernos en profundo contacto con la rea-

${ }^{2}$ E. BORÚS, Aprendiendo a vivir. Manual contra el aburrimiento y la prisa, Bilbao 1996, 77-78. 
lidad, nos abre perspectivas luminosas, nos ofrece horizontes amplísimos y llenos de riqueza, al mismo tiempo que la vida se simplifica, se libera de complicaciones, y deja de embrollarse en vericuetos que no llevan a ninguna parte.

Uno logra detenerse plenamente cuando un objeto o una persona ocupa todo el interés por un instante. Ese momento, cuando una sola realidad ocupa nuestra atención, es un tiempo vivido a pleno, con todo nuestro ser unificado en una sola dirección. Allí hemos alcanzado un verdadero encuentro, una fusión, una unión perfecta, aunque sea por un momento. No se trata necesariamente de una quietud física, porque esta experiencia puede producirse también en medio del entusiasmo de una actividad muy intensa. Esto sucede, por ejemplo, en un orgasmo entre dos personas que se aman. Pero hay muchas otras formas de unión que la mayoría de las personas experimentan pocas veces en la vida. Si pudieran multiplicarlas encontrarían una existencia mucho más plena.

\section{Presupuestos}

Si quisiéramos resumir en dos frases las convicciones interiores previas que hacen posible llegar a una detención perfecta, podemos destacar las siguientes:

\section{a. "Nada en este mundo es urgente ni absoluto"}

Porque para poder detenerme en algo o en alguien, dedicándole por un instante todas mis energías, mi interés, mi atención mental y afectiva, tengo que apartar por ese instante todo lo demás, para que nada me distraiga, para que todas mis energías se concentren sólo en ese punto. De otra manera, mis energías seguirán desconcentradas, dispersas, y no podré experimentar el encuentro pleno con esa realidad que tengo ante mí. Si hay alguna urgencia que me llena de tensiones, no podré prestar una atención serena y amorosa a esa persona o a esa cosa. Si hay alguna tarea, otras personas, otros proyectos que me parecen absolutos, estaré con mi mente ansiosa lejos de este presente, y no podré detenerme en él. 


\section{b. "Todo es importante"}

Porque cualquier cosa que me toque vivir es un desafío que Dios me presenta, es mi realidad, y por lo tanto merece ser vivida a pleno. Nada de lo que tenga que vivir debería parecerme insignificante. Todo es importante si es lo que me toca vivir.

San Francisco de Asís experimentaba esto a fondo, porque a cualquier cosa le llamaba "hermana", y así vivía un precioso amor universal. Estaba siempre a pleno donde le tocaba estar. Gozaba yendo donde le tocaba ir. Aceptaba ser lo que le tocaba ser. La capacidad de detenerse a veces se expresa en la capacidad de apasionarse y de entusiasmarse con toda el alma y todas las fuerzas en una tarea, en una realidad. Es vivir con total intensidad lo que haya que vivir.

Veamos un ejemplo concreto, tomado de mi propia experiencia:

"Una tarde de verano iba caminando por los cerros, en un lugar simple pero muy bonito. Yo no disfrutaba del paisaje, de la brisa, del sol, porque estaba inmerso en un montón de pensamientos, recuerdos, escenas que iban y venían por la mente.

Así pasaba el tiempo, y se me escapaba el placer de aquella tarde...

Hasta que escuché interiormente un llamado de Dios que me decía: "No hables más. Deja que hable yo".

Creí comprender ese mensaje. Entendí que tenía que acallar esos pensamientos inútiles que me distraían, y que tenía que escuchar lo que Dios quería decirme. Entonces, cambié aquellos pensamientos por otras reflexiones teológicas y espirituales sobre la presencia de Dios en la naturaleza, y luego pasé a reflexionar sobre otras cuestiones.

Pero volví a escuchar insistentemente: "No hables más, deja que hable yo". Claro, yo no había callado, no había permitido que Dios hablara. Sólo había cambiado unos pensamientos por otros, unas palabras por otras, y no era capaz de disfrutar calladamente de aquella tarde. Palabras, palabras...

Finalmente acepté que Dios me hablara. Simplemente dejé de alimentar los razonamientos, recuerdos y proyectos que atrapaban mi mente. Sólo comencé a prestar atención serenamente a los detalles del paisaje, sólo empecé a percibir con gozo el calor del sol y le permití al aire que me acariciara. Contemplé agradecido los colores, las líneas, las formas, y escuché el rumor del paisaje. Sin pensar en nada. $Y$ 
cada piedra, cada hierba, cada nube, comenzaban a ser inmensamente valiosas. Eran mi verdad, eran mi vida, eran mi presente, eran el mensaje de Dios.

En cada recodo del camino Dios me hablaba, pero no con razonamientos o reflexiones. En cada cosa, envolviéndome con los colores, las sensaciones y los sonidos, Dios me amaba. Así, simplemente, me hablaba de amor.

Aquella tarde terminé mi paseo agradecido, sintiéndome amado por Dios. Esa era mi verdad más grande, y por lo tanto, la palabra más importante que Dios me quería decir".

Pero es un error creer que sólo es posible detenerse ante la pura y bella naturaleza: el sonido de un arroyo, los colores de un atardecer en el lago, el azul de las montañas. Eso es sólo una parte de la realidad. Podemos detenernos y tomar contacto con cualquier cosa, también con las calles de una ciudad, con los ladrillos, con las antenas. Podemos aprender a unirnos con la ciudad y dejar de sentirla como algo extraño. No hay que contraponer la naturaleza a la obra del hombre. Porque si existe en la tierra un ser que tiene una mente, una creatividad y una capacidad de construir, significa que eso también es bueno. También un barrio desordenado y pobre tiene su secreta hermosura y su misterio que atrapa, si aprendemos a detenernos allí, en sus detalles, en su vida. Además, toda la realidad puede ser aceptada con serenidad tal como es, y también los edificios de una ciudad. Si en lugar de despreciarlos nos detuviéramos ante ellos prestándoles un poco de atención, apreciando sus formas y colores sin emitir juicios, poco a poco lograremos sentir esos edificios como parte de nuestra vida, y percibiremos algo de belleza en ellos.

\section{Intensidad vital}

Lo mismo vale para una actividad, porque esta capacidad de detenerse puede experimentarse en medio de una tarea intensa. Cuando alguien adquiere una verdadera habilidad que lo hace feliz, es porque ha dejado de preocuparse por lo que está alrededor, por el éxito, el fracaso, la mirada de los demás, el aplauso o los sentimientos de los demás. El artista ha logrado estar sólo en lo que hace, entregarse de 
lleno a eso. Entonces, el cantante en lugar de cantar, es cantado por la canción, el narrador es tomado por la historia o el poema que recita, un deportista se deja atrapar fascinado por el mundo de relaciones que se establece en el juego. Y entonces todo sucede de modo natural, todo fluye, sin dolor ni miedo. Es ese presente lo que cuenta, y nada más. Cuando es así, la persona confía en ese dinamismo que se ha apoderado de todo su ser y deja que todo suceda. Evidentemente, cuando uno ha logrado determinada destreza, esto se hace más fácil; pero también es cierto que la destreza será mayor cuanto más nos liberemos del temor. Nunca terminaremos de desarrollar una habilidad si no llega el momento en que nos entregamos completamente a esa actividad porque sí, y nada más que porque sí. Es lo que sucede en varias formas de lucha oriental, donde la persona pierde el temor cuando da todo de sí, y al mismo tiempo puede dar más de sí a medida que pierde el temor. Esto sucede cuando uno se olvida de todo lo que hay alrededor, y también del reloj, como si el tiempo no pasara, y no interesara. Tampoco interesa si cometimos errores; eso no nos perturba, ya que sólo interesa lo que está aconteciendo, y no lo que podría ser o lo que debería haber sido. Las grandes obras, las genialidades del arte, las mejores creaciones del hombre, han surgido en momentos receptivos, cuando alguien se ha dejado tomar, se ha dejado poseer por algo o por alguien.

Hay personas que prefieren la ansiedad, el nerviosismo de miles de tareas. Quieren hacerlo todo porque creen que eso es vivir. Pero no hacen nada con verdadera calidad, con un sentido profundo, con verdadero gozo. Es como si vivieran escapando de algo, quizás escapando de sí mismos en ese desorden. Por eso, cuando se liberan de alguna dificultad, necesitan encontrar otra. En realidad le tienen temor a la calma, y no valoran la paz. Confunden la paz con el aburrimiento y la monotonía. Pero no advierten que no hay nada más aburrido que la prisa permanente, porque así no pueden gozar de ninguna tarea. La verdadera paz es una agradable calma que nos mantiene fuertes y saludables para poder disfrutar intensamente de todo lo que la vida nos ofrece, también del trabajo. Es como llevar dentro del corazón un inmenso lago de agua mansa y calma en medio de la actividad más agitada. Dios es ese abismo de paz, pero al mismo tiempo lleno de vida, de riqueza y de hermosura. Nada de monotonía o aburrimiento. No olvidemos que la actividad más intensa es la del corazón. Un corazón 
lleno de la vida de Dios se siente pleno, fuerte, entusiasta, aunque esté en medio de un desierto. No necesita un permanente bullicio o una actividad afiebrada para sentirse vivo. Pero si tiene que actuar lo hace con todas las ganas sin perder la calma. No está adormecido. Está bien despierto y atento a la vida, pero domina siempre la situación porque confía en el poder de Dios. No se hace esclavo de sus planes; puede seleccionar las tareas y dejar para después lo que puede esperar. Así, en su existencia reina un orden lleno de vida.

La ansiedad nos convierte en personas superficiales, porque nos lleva a pasar rápidamente de una cosa a la otra, sin llegar a la profundidad de nada. El corazón ansioso no soporta la quietud; pero así no puede gustar del sabor más agradable de las cosas.

La Virgen María, que estaba libre de todo pecado, y vivía en la armonía de la gracia, era capaz de detenerse en cada cosa. Cuenta el Evangelio que ella estaba atenta a todo lo que sucedía con su hijo Jesús, y meditaba esas cosas en su corazón (Lc. 2, 19). Ella no se quedaba en la superficie, sino que rumiaba la vida, la saboreaba, la penetraba con la luz preciosa del amor. Es más, el Evangelio dice después que ella conservaba "cuidadosamente" cada cosa en su corazón (Lc. 2, 51). Ella no manoseaba los regalos de Dios, no tomaba a la ligera lo que Dios le regalaba o le presentaba. La ansiedad no tenía poder en su corazón o en su mente, y por eso no pasaba descuidadamente de una cosa a la otra, de una tarea a la otra, de un lugar a otro. Todo tenía su tiempo y su momento. Pidamos el don de ser así, delicadamente "cuidadosos" con todo lo que él nos conceda vivir.

\section{Detenerse ante el pobre para poder orar}

Aprender a detenernos es también aprender a detenernos ante los pobres, amándolos, percibiendo su inmenso y sagrado valor. Ser contemplativo es también poder reconocer esa inmensa dignidad de todo ser humano y apreciar los destellos de Dios en cada persona. Pero si sólo nos ejercitamos para detenernos ante lo que es armonioso y bello según los esquemas de la sociedad consumista, sólo seremos capaces de detenernos ante un cuerpo hermoso, proporcionado, limpio y sano. Nos convertiremos en seres selectivos, que pretendemos elegir a quién 
amar, y entonces seremos cada vez más egoístas, ciegos e insatisfechos. Así nos volveremos absolutamente incapaces de detenernos ante los pobres y de compartir con ellos nuestra vida. Por lo tanto, la actividad evangelizadora sólo se dirigirá con gusto a un grupo selecto de personas. La sabiduría de la Biblia nos enseña que de esa manera nos privaremos de la felicidad más profunda, nos quedaremos en la superficie. Nos sentiremos místicos porque podemos detenernos ante la naturaleza o ante una música relajante, o ante una idea, pero en realidad nuestro interior seguirá alejado de la realidad, incapaz de detenerse ante el mundo verdadero. Ese engaño malsano queda al descubierto si leemos algunos consejos bíblicos:

"Cuando des una comida o una cena, no llames a tus amigos, ni a tus hermanos, ni a tus parientes, ni a tus vecinos ricos. Porque si luego ellos te invitan a ti, esa será tu recompensa. Cuando des un banquete, llama a los pobres, a los lisiados, a los cojos, a los ciegos, y serás dichoso" (Lc 14, 12-14).

"¡Y serás dichoso!” dice Jesús. ¿Qué misterioso secreto de felicidad hay aquí? ¿Qué discreta y delicada luz nos quiere hacer descubrir este consejo del Señor?

En otro texto bíblico, se nos narra que Jesús se arrodilló a lavar los pies de sus discípulos, y después de hacerlo, les pidió que aprendieran a lavarse los pies unos a otros, y concluye diciendo: "Sabiendo esto, serán felices si lo cumplen” (Jn 13, 17). Otra vez Jesús ofrece un extraño secreto de felicidad: "iSerán felices si lo cumplen!”.

Ya en el Antiguo Testamento se encontraba esta misteriosa promesa. El profeta Isaías invitaba a compartir el pan con el hambriento, a recibir al pobre en la propia casa, a cubrir al desnudo, y luego hablaba de las consecuencias de todo eso: "Entonces brillará tu luz como la aurora y rápidamente se curará tu herida” (Is 58, 8). ¿En qué manual de autoayuda aparecen estos curiosos secretos de salud y de felicidad?

En realidad, estos textos bíblicos nos permiten desenmascarar las falsas técnicas de felicidad que no alcanzan a sanar de verdad los problemas del corazón. La intimidad del ser humano sólo madura en el amor generoso y no es feliz mientras no aprende a amar en serio.

En el encuentro cariñoso, sobre todo cuando el otro sufre o está discapacitado, no se trata de "ascender de grado, volviéndose cada vez 
más eficaz y buscando un reconocimiento, sino de descender, de perder mi tiempo"3.

Esta receptividad vivida en la acción mundana enriquece el encuentro con Dios en la oración privada. Así se evita que la oración privada caiga en la monotonía y que el encuentro con Dios pierda dinamismo, novedad y riqueza. Por otra parte, esta actitud receptiva y contemplativa ante el mundo de los demás, hace que luego ese mundo con toda su vida se haga presente en la oración, no sólo en la intercesión (por sus dramas) sino también en la acción de gracias (por sus valores). Luego de haber contemplado a Dios en la vida, puede contemplarse la vida en Dios.

El que sabe contemplar al mundo y recibir algo de los demás, llevará consigo a la oración privada los desafíos, las interpelaciones que ha recibido en la dispersión mundana, asumirá esa riqueza nueva, y así su encuentro con Dios se verá modificado. Reconociendo que Dios es el origen de todo lo bello que descubre en el mundo, podrá encontrar nuevos puntos de partida para la analogía y así enriquecerá su imagen de Dios.

Cuando la riqueza espiritual de una persona se expresa y se proyecta en la actividad, esa persona recibe siempre algo nuevo de ese mundo y de esas personas donde él explaya la actividad. Además, un evangelizador puede reconocer mejor la riqueza y la hermosura de lo que Dios ha sembrado en su propia intimidad cuando descubre la acción del Espíritu fuera de sí. Dejándose enseñar y dejándose evangelizar en la actividad, puede reconocer mejor la riqueza del Dios que toca su vida en la privacidad y puede dejarse enseñar por Dios en la intimidad. Porque en la relación receptiva con las personas y las cosas, se establecen conexiones mentales y afectivas que permiten explicitar riquezas del Evangelio que un individuo aislado no alcanza a percibir.

Digamos también que estamos 1lamados a ser contemplativos del ser humano como imagen de Dios, como reflejo sagrado de lo divino en la tierra. Si nos habituamos a tener esa actitud receptiva y no sólo donativa ante los demás, es posible que incorporemos sinceramente a los hermanos en nuestra oración solitaria.

3 J. VANIER, Amar hasta el extremo, Madrid 1997, 25. 
Estamos hablando entonces de una verdadera profundidad contemplativa que se vive en el encuentro con los demás; no sólo en una suerte de observación recogida o intimista, sino en medio de la misma actividad de servicio al hermano. Es una acción en la cual la hermosura y la dignidad del otro son intensamente percibidas por el corazón amante, porque el hermano es contemplado como reflejo de la gloria de Dios.

Las personas que han optado por "convivir" con los pobres y discapacitados, que no sólo les dan alguna ayuda material sino que comparten con ellos sus vidas enteras, nos enseñan el arte de detenerse místicamente ante ellos. Quiero mencionar como ejemplo el testimonio de Jean Vanier. Él indica que en el camino de comunión con los excluidos de la sociedad, a veces es difícil rescatar momentos de verdadera soledad para suspirar un poco en la presencia de Dios, y quizás aparezca el anhelo -y hasta la tentación- de una vida más "espiritual":

"Hace algunos años me fui de vacaciones con un grupo de quince personas del Arca. Nuestra vida juntos era sencilla y relajada. Había que cocinar y limpiar, y muchas personas del grupo tenían una deficiencia profunda. Como yo me levantaba temprano, me iba con tiempo a un monasterio que se encontraba a quinientos metros para participar en la oración de los monjes. Disfrutaba mucho de esos momentos de silencio y de paz. Desayunaba con los monjes y después, hacia las ocho, volvía a nuestra casa con el corazón pesaroso. Después de esas benditas horas, sentía cierto temor por reencontrarme con lo cotidiano: preparar el desayuno, levantar a Loïc, bañarlo, despertar a los demás asistentes, etc. Conforme iban pasando los días mi corazón se iba volviendo más y más pesaroso. ¡Me encontraba tan bien con los monjes! Me daba cuenta de que tenía que volver la mirada a mi propia vocación para aceptarla plenamente"4.

Hacia falta convencerse de que los momentos de oración "no son tanto un método para conocer especulativamente la esencia divina, sino para conocer a Jesús y su llamada en orden a una acción"5.

4 Ibid, 40-41.

${ }^{5}$ I. ELLACURÍA, Misión actual de la Compañía de Jesús, en Revista Latinoamericana de Teología 10 (El Salvador 1993), 116. 
Sin embargo, la vida con los discapacitados no carecía de momentos de alta contemplación, de un místico "detenerse" ante un pobre o un discapacitado que provoca una feliz liberación:

"A veces Loïc se sienta en mis rodillas. Pequeño, pobre, incapaz de hablar a pesar de sus cuarenta años, está ahí, silencioso. Él me mira y yo le miro. Estamos en comunión el uno con el otro... Con las personas que sufren una deficiencia mental como Lö̈c, vivimos esos momentos de contemplación, llenos de silencio y de paz. Él me mira y yo le miro. Momentos de curación que unifican el cuerpo y el espíritu. Al identificarse con los pobres, Jesús recuerda que se identifica con el pequeño que hay en cada uno de nosotros. Lo importante es estar confiado, abierto, maravillado como un niño. Cada persona es sagrada, sean cuales fuesen su deficiencia, su fragilidad, su cultura..."6.

El amor hace posible que en esta relación contemplativa nos descubramos verdaderamente necesitados del otro, por más limitado que él sea. Así se puede acoger la preocupación del Magisterio católico al condenar ciertas expresiones del quietismo de Fénelon, que proponía "un estado habitual de amor a Dios que es caridad pura y sin mezcla alguna de motivo de interés propio" (DS 2351), donde "no queremos nada para nosotros" (DS 2355). En una criatura limitada, imperfecta y frágil como el ser humano en camino, el amor no puede concebirse sin un legítimo interés, que consiste en un reconocimiento mental y afectivo de la necesidad de ser completado por los demás, en la serena convicción de ser vulnerable e indigente. Esta situación ante el otro, cuando es transfigurada por la gracia, se convierte en una "gratuita receptividad". Esa gratuidad no consiste en que uno se considere completamente independiente o prescindente de lo que el otro pueda ofrecer, sino en la convicción interior de que eso que necesitamos no puede exigirse a los demás y sólo puede ser recibido como regalo. Sólo esta actitud "gratuitamente interesada" hace posible una sincera acción de gracias por lo que recibimos de Dios a través de los demás y abre el camino a una oración personal donde nos dejamos amar en serio por Dios.

6 J. VANIER (cit) 37. 


\section{El corazón puesto en la variedad mundana}

Ya que Dios amorosamente nos ha colocado en esta tierra, el amor al mundo es necesario para ser fieles a la propia identidad y para que podamos comprometernos en el proyecto divino de mejorarlo. Sin embargo, viejas y nuevas formas de espiritualidad provocan en muchos cristianos una inclinación a construir y habitar pequeños sectores privados. Por eso parece conveniente profundizar las motivaciones de una sana teología que inspiren una fuerte pasión por el mundo externo.

Podemos pensar que el ser humano está llamado a la gloria celestial, que allí está su destino último, y entonces deducir que esta historia terrena es imperfección. Además, si la gloria celestial se entiende como un estado de impasibilidad, donde -ciertamente- nos liberamos de las tensiones, angustias, cansancios y dolores de esta vida, entonces resulta difícil atribuir algún valor espiritual a la actividad en el mundo, a las fatigas, a las relaciones humanas a veces rutinarias y a veces desafiantes. Pensamos que todo eso no tiene nada que ver con el cielo al cual estamos llamados, y por lo tanto -concluimos- no tiene en sí mismo un valor espiritual. Parece que eso sólo vale si es tolerado y ofrecido en unión con Jesús sufriente.

En esta concepción, sólo tendría valor propio aquello que se asemeje al cielo: la quietud de un monasterio, el silencio, la serenidad, la ausencia de tensiones, la concentración que evite la dispersión.

Pero el hecho es que esta historia no es sólo una copia imperfecta de la gloria celestial, sino que tiene su especificidad, querida por Dios, en cuanto es camino y proceso. Su valor propio no está en lo que tenga de semejante al cielo, porque fue querida por Dios como historia. No fue pensada por Dios como una versión imperfecta del cielo.

En el cielo, de hecho, no existirá la Eucaristía, y sin embargo ésta es el modo más excelente de encuentro con Cristo en la historia. En esta especificidad de la historia es donde la Eucaristía hace presente, para los caminantes débiles y hambrientos, al Cristo que en la gloria es pura evidencia y saciedad para los bienaventurados. Así, en esta historia que debe ser construida por la comunidad, la Eucaristía es alimento y fortaleza, es mediación y manifestación perfecta de la gracia.

Igualmente, el proceso histórico que permite que un pobre mal alimentado comience a comer adecuadamente es algo de inmenso 
valor, aunque eso no sea en sí mismo un anticipo del cielo, porque en el cielo ya no hay necesidad de comer.

Es cierto que el amor es lo que da valor a esa preocupación concreta por el pobre, pero en esta historia el amor debe expresarse necesariamente en la preocupación concreta por el alimento del pobre como reflejo y prolongación de la misericordia de Dios.

Además, esta historia fue querida por Dios como un proceso que verdaderamente influye en la gloria celestial. Todo lo que se logre de verdadero, bueno y bello en el camino de la historia pasará a enriquecer y a embellecer el Reino celestial (GS 39).

Que algunos estén llamados a la oración solitaria no debe hacer olvidar que la inmensa mayoría de los cristianos, que viven en la sociedad, ha de responder al llamado de Dios para mejorar este mundo.

\section{Crecer en el encuentro con el mundo}

Por lo tanto, no puede pensarse que el valor de la espiritualidad se mide por los momentos de soledad, quietud y calma que permiten un encuentro sereno y concentrado con Dios, entendiendo que allí se produce el anticipo del cielo. Si entendiéramos así la espiritualidad, entonces el diálogo de un evangelizador con el mundo y la cultura moderna no podría brindar ningún tipo de enriquecimiento espiritual y de ninguna manera podría entenderse como parte y expresión de la espiritualidad.

Es importante aceptar que somos caminantes en esta historia que está en permanente cambio y movimiento. Para nosotros eso tiene un inmenso valor porque Dios ha querido amorosamente que, por ahora, seamos caminantes. Si nos resistimos a ese dinamismo, estaremos siempre llenos de tensiones y angustias:

"Cuando insistimos en ser siempre los mismos, nos deformamos... Mucha miseria humana resulta de no formar parte del proceso de eliminar lo caduco o reformar lo existente"7.

Nuestra espiritualidad cristiana es histórica. Es decir: se vive dentro de una historia humana y no en el cielo. Pero algunas personas se

7 S. KELEMAN, La experiencia somática, Bilbao 1997, 105. 
resisten a vivir en este mundo, y quisieran refugiarse en una especie de pequeño cielo, escondidos y protegidos del mundo. O pretenden salir de esta tierra en una suerte de vuelo cósmico, evadiéndose de todo compromiso, tratando de liberarse de todo lo que les provoque resistencias. Eso sería como volver al útero de nuestra madre y renunciar a la vida, al crecimiento, a la felicidad verdadera y fecunda que Dios ofrece.

Los hijos de Dios estamos llamados a un profundo amor a los demás y a introducirnos de lleno en este mundo, en esta historia humana, en la vida de la gente. Soñamos aportar algo para la felicidad de los demás y dejar este mundo mejor que como lo hemos encontrado. Y el Dios de amor que tratamos en la oración nos impulsa a introducirnos en el mundo para mejorarlo, nos da una apasionante misión en esta tierra.

Cuando aceptamos eso, dejamos de resistirnos ante los reclamos de la historia y de la gente, porque nos interesa construir algo mejor. Así lo hicieron San Francisco de Asís, Santa Catalina de Siena, Martin Luther King, Mahatma Gandhi, y muchos otros que fueron felices y plenos tratando de mejorar la sociedad terrena. Ninguno de ellos pretendió evadirse en un pequeño paraíso de tranquilidad o soledad, sino que se entregó como instrumento de Dios para hacer el bien a mucha gente, con la esperanza de que siempre algo puede cambiar para gloria de Dios. En este sentido, la Iglesia ha hecho la siguiente advertencia, que tiene una tremenda importancia:

"Auténticas prácticas de meditación provenientes del Oriente cristiano y de las grandes religiones no cristianas, que ejercen un atractivo sobre el hombre de hoy -dividido y desorientado-, pueden ser un medio adecuado para ayudar a la persona que ora a estar interiormente distendida delante de Dios, incluso en medio de las solicitudes exteriores. Sin embargo, es preciso recordar que la unión habitual con Dios... no se interrumpe necesariamente ni siquiera cuando hay que dedicarse, según la voluntad de Dios, al trabajo y al cuidado del prójimo... Efectivamente, la oración auténtica, como sostienen los grandes maestros espirituales, suscita en los que la practican una ardiente caridad que los empuja a colaborar en la misión de la Iglesia y en el servicio a los hermanos"8.

${ }^{8}$ CONGREGACIÓN PARA LA DOCTRINA DE LA FE, Carta sobre algunos aspectos de la meditación cristiana, Roma 1989, 28. 


\section{Agobiados por la multiplicidad}

Esto mismo vale si nos referimos a la multiplicidad con la cual nos topamos en nuestro encuentro con el mundo externo. Si dependiéramos excesivamente de algunas concepciones filosóficas, diríamos que la multiplicidad de las criaturas es una degradación, una imperfección, comparada con la perfecta unidad divina. En ese caso, lo más perfecto sería siempre una oración concentrada que nos unifique en la presencia de Dios, evitando todo tipo de dispersión en la multiplicidad imperfecta de lo creado.

Hay razones existenciales para pensar así. Si uno toma contacto con la complejidad de la vida social, si se relaciona asiduamente con las personas, si vive en el mundo como los demás, pero al mismo tiempo siente el atractivo de la oración, del silencio o de la reflexión reposada, entonces es comprensible que se sienta abrumado por la dispersión, por la variedad que existe en lo mundano, por las innumerables formas de pensar, de vivir, de actuar, por la multitud de productos fabricados por el hombre, por la cantidad incontable de tareas, intereses, preocupaciones cotidianas de la gente. La misma actividad evangelizadora, en contacto con esa variedad, será vivida siempre como una cierta "imperfección permitida".

Aquellos que sienten ciertas inclinaciones místicas suelen pensar que en el fondo toda esa multiplicidad es cáscara, superficialidad, distracción que nos aparta de lo único verdaderamente importante. Por eso en el fondo creen -aunque nunca lo consigan- que el ideal es liberarse de la seducción y del vacío de la multiplicidad y de su ruido. Procuran reducir su mundo a la mayor unidad y simplicidad posible, creyendo que así se encuentran mejor con el Uno y su inmutable verdad.

Esta ideología teórico-práctica, tan actual, es heredera de Parménides, Plotino, Spinoza, Schelling, Schopenhauer, y de diversos gnosticismos y maniqueísmos que influyeron en las corrientes de espiritualidad, provocando el rechazo de lo múltiple, de la diferencia, de la variedad.

Evidentemente, esto no podría sustentar nunca el entusiasmo por penetrar el mundo, la pasión por el encuentro con los demás, la búsqueda de la verdad en la escucha y el diálogo, el gozo de buscar a otros para dar y recibir, el gusto por evangelizar. La vida y las ordinarias 
inquietudes de las personas parecerán siempre mediocres, todo tendrá sabor a sinsentido.

En ese contexto de una posmoderna "fuga mundi" ¿cómo es posible alimentar actitudes de apertura, valoración, empatía y comunión?

Las actitudes nuevas dependen de convicciones que se han hecho carne. Después de tanto pensar, gustar y profundizar una buena idea, los distintos intentos van logrando que esa idea se haga pasión y comience a impulsar a la persona en un nuevo estilo de vida.

En toda espiritualidad que verdaderamente movilice hacia el otro y hacia el mundo, hay un substrato de convicciones apasionadas.

La pregunta es: ¿Qué convicción profunda hace falta en un creyente para alimentar el diálogo sincero con el mundo y la pasión por evangelizarlo?

La pregunta es clave en el contexto privatizador actual. Porque las experiencias religiosas convertidas en artículo de consumo, para alcanzar paz y armonía psicológica, no son ciertamente un gran impulso para transformar el mundo, para preocuparse por los demás, para encontrase con la vida de los otros valorando y acogiendo sus inquietudes variadas. Aún las valiosas espiritualidades monásticas, trasplantadas a los agentes pastorales, pueden convertirse fácilmente en experiencias solitarias y subjetivas que lleven a mirar con cierto desprecio (o sólo con tolerancia) todo lo mundano con su multiplicidad.

Esas espiritualidades suelen producir seres que intentan cumplir su misión en el mundo, pero sintiéndose en el fondo como atados a una obligación voluntarista que los mantiene en la superficie, en la mediocridad de lo múltiple, en la insatisfacción y en el vacío.

Las conversaciones de las personas, las inquietudes del día a día, las minucias de la historia de las familias, los vaivenes de la sociedad, las diversas sensibilidades musicales o artísticas, las costumbres, toda la múltiple vida del mundo parecerá inútil vanidad de la cual conviene preservarse. Así, esta forma de pensar y de sentir provoca seres malhumorados, hoscos, melancólicos, aislados y egoístas.

El punto de partida para liberarse de la convicción venenosa que alimenta este proceso, consiste en profundizar la convicción opuesta, haciéndola carne y pasión. Es lo que intentaremos a continuación. 


\section{El valor de la multiplicidad mundana}

La dispersión mundana no es una degradación detestable de la Unidad. Al contrario, la realidad es que la multiplicidad y variedad de criaturas que Dios ha hecho es un reflejo de su inagotable riqueza, y por lo tanto son la mediación que nos permite captar los diversos aspectos de la verdad.

Bien enseñaba Tomás de Aquino que "la distinción y la multitud de las cosas provienen de la intención del primer agente, que es Dios" (ST I, 47, 1). Él las creó múltiples y variadas "para comunicarles su bondad y representarla por ellas". Porque "esta bondad no podría representarse convenientemente por una sola criatura" (ibid). Ninguna de las criaturas representa perfectamente a su prototipo" ( $\mathrm{ad} 2)$, y por eso necesitamos captar la variedad de las cosas en sus múltiples relaciones $(47,2$, ad $1 ; 47,3)$.

Entonces, el encuentro con la variedad de los seres, de los objetos, de las tareas, gustos, opciones y proyectos de la gente, no es una lamentable distracción o una imperfección tolerable, sino una preciosa y necesaria mediación para reconocer a Dios como un Ser inmensamente rico y pleno, de manera que no limitemos nuestra imagen de Dios a lo que pueda reflejarse en un mundo reducido y cerrado.

Mientras más nos polarizamos en un sector reducido de la realidad, en una acotada porción de gustos privados, más perdemos perspectiva y riqueza. Por más perfecta que sea una criatura, una imagen, un símbolo, una forma de pensar, una manifestación artística, un lugar, nunca será una mediación suficiente para manifestarnos la riqueza y la hermosura de Dios. Él ha querido que "lo que faltaba a cada cosa para representar la bondad divina, fuera suplido por las otras" $(47,1)$. En la belleza que resulta de la relación entre las cosas, la bondad y la verdad se manifiestan más acabadamente que en la más perfecta de las criaturas. Por eso, "el universo no sería más perfecto si en las cosas hubiera un solo grado de bondad" $(47,2)$, aunque se tratara del grado mayor de perfección posible. La perfección de algo aislado, si no permite captar la belleza de la variedad en sus relaciones, atentaría contra la belleza misma. En el ejemplo de S. Tomás, esto sucedería, por ejemplo, si todas las partes de un animal tuviesen la perfección de los ojos (ad 1). La comunión de lo diverso, según el modelo de la Trinidad, siempre 
será infinitamente más perfecta que la unidad monolítica sin matices de una ideología o de una obsesión.

Por lo tanto, es sano y conveniente estar informado sobre la diversidad de cosas, lugares, costumbres y situaciones; escuchar hablar sobre todo tipo de artes y oficios; dialogar con cualquiera sobre las cosas que le interesan o le atraen; frecuentar ambientes variados; escuchar música de distintos estilos, etc.

De ahí que en la Biblia se considere sabio al rey Salomón porque "habló sobre las plantas, desde el cedro del Líbano hasta el musgo que brota en el muro; habló de los cuadrúpedos, de las aves, de los reptiles y de los peces" $(1 \operatorname{Re} 5,13)$, y también invita a contemplar la tarea del artesano, el herrero, el alfarero (Sir 38, 27-30) porque "cada uno se muestra sabio en su tarea" $(38,31)$.

Todo esto nos permite comprender por qué podemos hablar de una espiritualidad que se vive y se expresa en el encuentro con los demás, en el diálogo con la cultura, en el trato con el mundo moderno lleno de desafíos variados y de nuevas posibilidades.

Apasionarse con la variedad de la vida, detenerse ante ella, contemplarla, gustarla, sin cerrarse a la parte de bien y de verdad de cada realidad; percibir las relaciones que se establecen entre las cosas y acontecimientos. Esto nos permite apreciar mejor la verdad en su conjunto y captar más adecuadamente la bondad divina. Sólo así es posible evitar espiritualidades privatizadoras y malsanas que nos apartan de la rica vida del mundo donde Dios nos ha inserto y que debilitan el impulso evangelizador. 